\title{
Enhancing primary school students' competencies in step by step controllable argumentation using a new learning environment
}

\section{Dekriati Ate}

Department of Mathematics Education, STKIP Weetebula

Jln. Mananga Aba, Desa Karuni, Kec. Loura, Kab. Sumba Barat Daya, 87256, Indonesia

E-mail: dekriati@gmail.com

\section{ARTICLE INFO}

\section{Article history}

Received: 28 October 2020

Revised: 19 January 2021

Accepted: 9 September 2021

\section{Keywords}

addition and subtraction of integers, design research, metacognitive teachinglearning culture

Scan me:

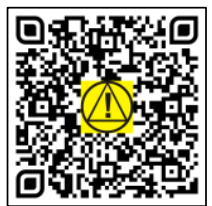

\section{ABSTRACT}

For the goal of raising the mathematical performance of students, the quality of teaching has to be improved in the direction that critical thinking and a step-bystep controllable argumentation have to be established. Metacognitive activities of teachers and students can support this. The goal of the design research presented in this paper is to show how metacognitive activities in classroom discussions can be fostered and the mechanisms can be uncovered. For this purpose, on the one hand, a new learning environment - designed for learning addition and subtraction of integers in grade four - has been created. On the other hand, the teacher and the students have been consequently educated to practice new behavior during the lessons. This pilot study is carried out in Sumba, in a regular class, grade four, consisting of 28 students. The lessons had been video graphed; selected pieces of the public discussions have been transcribed. Teacher's and learners' utterances and their interplay have been classified using a particular coding system developed for those purposes. The pattern of classifications has been the basis for interpreting the metacognitivediscursive learning culture. One result of the study is that students even in grade four accept such a learning environment; they practice inventing and analyzing strategies in this field of algebra as it would be a game with step-by-step controllable argumentations. After that, an astonishingly short time of educating students to practice metacognitive activities, both in oral discussions as well as in written answers to relevant formulated questions.

This is an open access article under the CC-BY-SA license.

How to Cite: Ate, D. (2021). Enhancing primary school students' competencies in step by step controllable argumentation using a new learning environment. Jurnal Riset Pendidikan Matematika, 8(1), 73-82. https://doi.org/10.21831/jrpm.v8i1.35322

\section{INTRODUCTION}

For the goal of raising the mathematical performance of students, the quality of teaching has to be improved in the direction that critical thinking and stepwise controllable argumentation have to be established. Metacognitive activities of teachers and students can support this. A lot of research has shown that metacognition greatly impacts the outcome of learning (Veenman et al., 2006, Schneider \& Artelt, 2010). One key to improving the metacognitive teaching culture in a mathematics class is the use of specially designed learning environments.

This article presents how a new learning environment - designed for learning addition and subtraction of integers in grade four - can foster metacognitive activities in classroom discussions. The essence is that the learning environment is based on a set of rules which, on one side during a game, have to be strictly followed, and on the other side, their sequence has to be strategically invented before practicing the single rules.

The integers are a crucial topic for students to learn due to its usefulness in solving various problems in daily life as well as a prerequisite material for studying other concepts in algebra (Musser et al., 2005). However, studies showed that many students still consider this topic difficult. Vlassis 
(Bofferding, 2010) said that, in particular, students have trouble making sense of the changing role of the minus sign. Students claim that two minuses in a problem mean a plus $($ e.g., $-1+(-5)=6)$, and they answer a problem such as $6+(-2)$ by adding 2 and then subtracting 2 . In addition, Van de Walle et al. (2008), the students are often confused to determine the greater numbers and to determine the direction of movement when performing arithmetic operations. Since designing a proper learning environment, learning mathematical operations with integers is a complex and challenging task, teachers have difficulties making learning integers meaningful and joyful for their students (Putri, 2011).

A deeper analysis leads to the insight that, on the way of extending the concept of natural numbers to integers, deficits in understanding the previous concepts come to the surface. From a cognitive point of view, it is not the best way to introduce numbers like objects with specific properties (Schwank, 2011). These mathematical concepts should be regarded as procepts (Gray \& Tall, 1994), which means that the process of its use determines the meaning. The concept number receives its meaning from its use and its role in a mathematical framework.

To introduce the concept of numbers, two different approaches principally exist: on the one hand, the focus is laid on the number of objects in a set of objects (cardinal aspect), on the other hand, the order of numbers is crucial (ordinal aspect). Research findings indicate that on the way of introducing the concept of numbers in early mathematical education, the focus should be laid on the ordinal aspect (Brainerd, 1979; Schwank, 2005; Schwank \& Schwank, 2015). Schwank (2010) presented and tested an idea, how even at a preschool level, the consideration of the ordinal aspect can be combined with a process orientation during movements.

Looking for a theoretical background and practical ideas as well to introduce integers, one may follow the Realistic Mathematics Education (RME) approach, which is well known and appreciated in Indonesia. This approach is based on Hans Freudenthal's view that "mathematics is a human activity" where students are not passive recipients. The students need to have opportunities to reinvent mathematical concepts through activities that they have experienced themselves (Zulkardi, 2002).

Coming from this background, it seems obvious to use a context that is a part of the children's surrounding reality. However, reality can also mean part of the children's imagination, as fairy tales, theatre, or games are (Nowińska, 2015). It is often reported that a suitable context for primary school children can be packed in educative games because primary school students love to play (Fosnot \& Dolk, 2001). A variety of games has been used in some studies, such as Muslimin et al. (2012), who used the "congklak" game for learning subtraction of integers in grade four, Prahmana et al. (2012), who used traditional Indonesian games for learning multiplication. Pintér (2010) sums up the influence of the use of the game in math classes as a result of her dissertation as follows: "Playing a game is not only fun, but the students can learn more effectively through activities and participation rather than passive instruction since they are usually better motivated and more active in reaching their goals. Games provide a visual representation of the problem through manipulative operations in a social context. They can increase students' knowledge, and they influence their cognitive and social development."

Games may be a good choice as far as the world of games provides a microworld (Schwank, 1995) and a system of metaphors in which an understanding of the necessary axiomatic approach can be introduced to the children. The meaning of a play figure is, for example, not given by the figure but by the rules of using it in the game. In a microworld, the occurring concepts, relations, and operations should function as formalized in mathematics. Therefore, in a microworld, the names and denominations are chosen as near as possible to those used in mathematics. During the teaching-learning process, it should be elaborated with the students why specific denominations are chosen or which disadvantages result in other denominations. In mathematics terminology, this can be expressed as follows: The microworld has to be isomorphic to that part of mathematics, which the student has to understand and learn in the following - including the formalization used. It is not sufficient that the specific mathematical theory is used in the model. The microworld should function precisely as the mathematical theory, including the possibility of formulating insights (theorems) and creating (define) new operations or relations.

The game Jumping forth and back on the number line, which is used in our teaching experiment in grade 4 , is designed as a microworld for understanding the mathematical idea of integers. It follows the idea of Cohors-Fresenborg (2013). For the students, there has been written a workbook, from which the following examples are taken. The Microworld Jumping forth and back on the number line and its relation to the axiomatization of integers is explained as follows. 


\section{Addition and Subtraction within Natural Numbers}

In the first step, we acquaint the students with a simple version of the game: On a playground, they have to put a pawn on the playing field (Figure 1), then throw the so-called number dice and jump with the pawn so many steps as diced. The students also learn how this task corresponds to the notation of a traditional arithmetical problem.

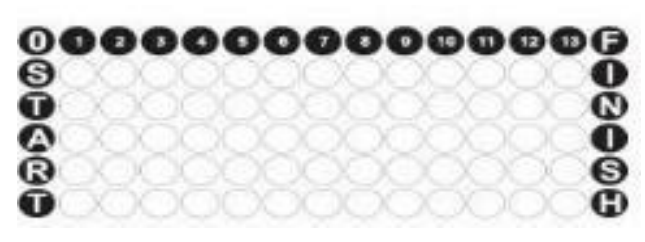

Figure 1. The playing field for steps 1 and 2

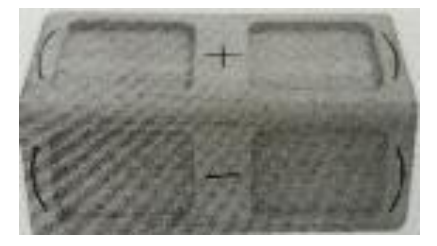

Figure 2. Dice for moving direction

In the second step, the students use what they have learned in grade 2 about subtraction (of a smaller number from a given one): subtraction reverses an addition. In the game, it means that the pawn has to jump backward. For this purpose, we introduce new dice for moving direction (Figure 2). The pawn now receives a face so that jumping forth and back to the viewing direction is defined.

As the addition is a binary function, the dice for moving direction is constructed in the way that left and right from arithmetic operator there is a space as a symbol of an argument place or a variable. Into this place, "something" can be inserted. In the pupils' workbook, the dice's abstraction for moving direction is introduced, as shown in Figure 3. The meaning of these signs is as follows:

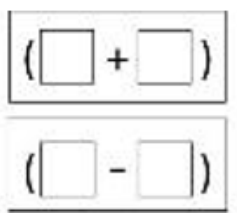

Move the pawn forwards in viewing direction

Move the pawn backwards in viewing direction

Figure 3. Schema of the dice for moving direction

Rules of the game: (1) put the pawn at any place on the playing field with its face looking to the right; (2) throw the dice for moving direction; (3) throw the number dice; (4) move the pawn based on the number shown by the number dice; (5) after every jump, the face of the pawn has to be turned to the player so that a concatenation of several different movements causes no mathematical difficulties.

\section{First insights of jumping forth and back}

For this game up to now, the following insights are obvious, which correspond to axioms of the corresponding mathematical structure:

$\mathrm{N}^{\mathrm{h}}$ : If the pawn starting from field $O$ jumps $x$ steps towards the viewing direction, the figure stands on field $\mathrm{x}$ afterward.

$\mathrm{I}^{\mathrm{h}} \quad$ : If the pawn starting from field $x$ first jumps $y$ steps towards the viewing direction, and then again $y$ steps backward to the viewing direction, in the end, the figure stands on field $x$ again.

$\mathrm{K}^{\mathrm{h}}$ : The following movements have the same result: The pawn starting from field $x$ jumps $y$ steps towards the viewing direction or the pawn starting from field $y$ jumps $x$ steps towards the viewing direction. A kind of associative law is true, but this is not discussed with the pupils in grade 4 .

$\mathrm{A}^{\mathrm{h}}$ : The following movements have the same result: The pawn starting from field $x$ first jumps $y$ steps towards the viewing direction and afterward $z$ steps towards the viewing direction; or the pawn starting from field $x$ jumps $(y+z)$ steps towards the viewing direction.

Understood as a mathematical contract (system of axioms), this can be written with the following paragraphs (axioms); which is, of course, not done with the pupils in grade 4:

$\mathrm{N}^{\circ}$ : For all numbers $x:(\square \circ x)=x$

$\mathrm{I}^{\sim} \quad:$ For all numbers $x$ and $y:((x \circ y) \diamond y)=x$

$\mathrm{K}^{\circ}:$ For all numbers $x$ and $y:(x \circ y)=(y \circ x)$

$\mathrm{A}^{\circ} \quad$ : For all numbers $x, y$ and $\left.z:((x \circ y)) \circ z\right)=(x \circ(y \circ z))$

This contract determines how these numbers have to be dealt with. However, it is not determined, what these numbers are, or what is meant by numbers. Everybody may imagine something different by 
numbers, and the binary operations used, as long as the paragraphs are fulfilled. The Paragraph $\mathrm{I}^{\sim}$ used in this contract does not force the pawn to move to the leftover field 0.

\section{Addition and Subtraction within the integer}

In the workbook, there is written about the following task: The pawn stands on field 3 and has to move 5 steps backward. The denomination $(O-a)$ first chosen makes sense from a mathematical point of view, as constructing an opposite number is in our concept not anchored in the system of axioms but is managed by a definition of the inverse function:

\section{D: For all numbers $x:(-x)$ is an abbreviation for $(0-x)$}

Therefore, in the future, the names of fields "left from zero" are $(-1),(-2),(-3), \ldots$, as it is done on the complete playing field shown in Figure 4.

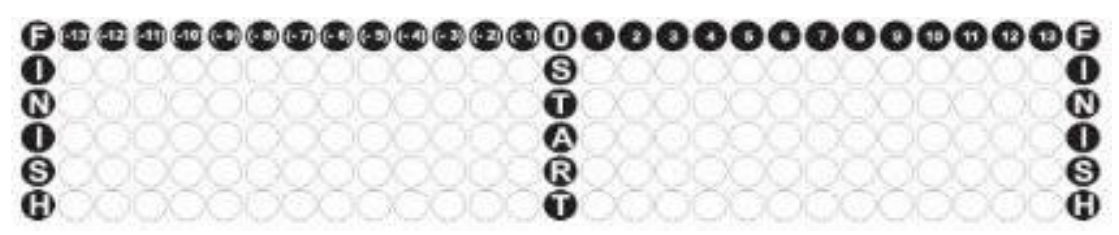

Figure 4. Playing field

The next step in the teaching unit is that students make the experience - by suitable exercises that starting on these new fields, one can come back to fields named by natural numbers. That means that the jumping to the left over the field 0 can be canceled by a suitable movement. This corresponds to the following axiom:

$$
\mathrm{I}^{\diamond}: \text { For all numbers } x \text { and } y:((x \diamond y) \circ y)=x
$$

Furthermore, the following is obvious in the microworld jumping forth and back; it allows to change the sequence of jumping forth and jumping back:

\section{$\mathrm{V}^{\mathrm{h}}$ : The following movements have the same result:}

The pawn starting from field $x$ is first jumping $y$ steps towards the viewing direction, and afterward, $z$ steps backward the viewing direction; or the pawn starting from field $x$ is first jumping $z$ steps backward the viewing direction, and then $y$ steps forwards.

Understood as a mathematical contract (System of Axioms) this can be written with the following paragraphs (axioms); which is of course not done with the pupils in grade 4:

$\mathrm{N}^{\circ}$ : For all numbers $x:(\square \circ x)=x$

$\mathrm{I}^{\diamond} \quad$ : For all numbers $\mathrm{x}$ and $y:((x \diamond y) \circ y)=x$

$\mathrm{K}^{\circ}:$ For all numbers $\mathrm{x}$ and $y:(x \circ y)=(y \circ x)$

$\mathrm{A}^{\circ} \quad$ : For all numbers $\mathrm{x}, y$ and $\left.z:((x \circ y)) \circ z\right)=(x \circ(y \circ z))$

$\mathrm{V}^{\circ \diamond}$ : For all numbers $\mathrm{x}, \mathrm{y}$ and $\left.\mathrm{z}:((x \circ y)) \diamond z\right)=((x \diamond z) \circ y)$

\section{METHOD}

Our study is design research that consists of three main steps: preparing for the experiment, design experiment, and retrospective analysis in the sense of Gravemeijer and Cobb (2006, p.19). In preparation for the teaching experiment, we had developed a new approach for introducing whole numbers in primary school as described at the end of the introduction. An extra-trained teacher, who only joined the class for teaching this lesson sequence, had done the teaching. The training addressed both aspects, the new mathematical approach as well as a metacognitive-discursive learning culture. The pilot study was carried out in Sumba, in a regular class, grade four, consisting of 28 students. One goal of the pilot study was to show that - by a suitable learning environment in combination with a new learning culture - it will be possible to change the behavior of the learners in the classroom: They should be educated to practice metacognitive activities in an elaborated discourse. It was an open question how far girls grown up in a very paternalistic society - would debate in public discussions, even with boys. The lessons had been video graphed; selected pieces of the public discussions have been transcribed. The utterances of both teachers and learners and their interplay have been classified using a particular coding 
system developed for those purposes. The pattern of classifications has been the basis for interpreting the metacognitive-discursive learning culture. I was categorizing the system of Cohors-Fresenborg and Kaune (2007) to detect the metacognitive activities of the teacher and the student. They developed a category system for an interpretative, transcript-based analysis of metacognitive and discursive activities. This paper uses a new version of that system (Cohors-Fresenborg et al., 2014; Cohors-Fresenborg $\&$ Nowińska, 2021). This category system decomposes metacognition in planning, monitoring, and reflection, not only in mathematics lessons.

Using the categorizing technique of Cohors-Fresenborg and Kaune (2007), the pieces of text, which are categorized by the indicated category, are coded based on Table 1.

Table 1. System for categorizing metacognitive activities during stepwise controlled argumentation in mathematics lessons

\begin{tabular}{|c|c|c|}
\hline No. & Classification & Description \\
\hline 1. & P1a & $\begin{array}{l}\text { Indication of a focus of attention, in particular about tools/methods to be used or } \\
\text { (intermediate) results or representations to be achieved }\end{array}$ \\
\hline 2. & $\mathbf{P 2}$ & Planning metacognitive activities \\
\hline 3. & M1 & Controlling of a subject-specific activity \\
\hline 4. & M2 & $\begin{array}{l}\text { Controlling of terminology/vocabulary used for description/explanation of a } \\
\text { concept }\end{array}$ \\
\hline 5. & M3 & Controlling of notation/ representation \\
\hline 6. & M4 & $\begin{array}{l}\text { Controlling the validity or adequacy of tools and methods used, in particular about a } \\
\text { planned approach or a modeling approach }\end{array}$ \\
\hline 7. & R1a & $\begin{array}{l}\text { Analysis of the structure of a subject-specific expression without taking into con- } \\
\text { sideration any additional rewriting or reorganization }\end{array}$ \\
\hline 8. & $\mathbf{R 3 b}$ & Result of reflection expressed by a wilful use of a (subject-specific) representation \\
\hline 9. & R4 & $\begin{array}{l}\text { Analysis of the effectiveness and application of subject-specific tools or methods/ } \\
\text { indication of a tool needed to achieve an intended result }\end{array}$ \\
\hline 10. & R6a & $\begin{array}{l}\text { Reflection-based assessment or evaluation about the issue discussed/content/tasks } \\
\text { /text, e.g., pointing out to the essential aspects or ideas, drawing an (interim) balance, } \\
\text { giving a summary, assessment of comprehensibility/ difficulty }\end{array}$ \\
\hline
\end{tabular}

An utterance is classified by a sequence of up to 5 letters and numbers. The center consists of a capital letter ( $\mathrm{P}$ for planning, $\mathrm{M}$ for monitoring, $\mathrm{R}$ for reflection) and 3 numbers for the subcategory; in some cases, there follows a small letter for further specification). Sometimes there exists a prefix of up to two italic small letters, to indicate by using $d$, if there is a demand for an activity, to indicate by using $r$, that the activity is connected with giving a reason, or to indicate by using the combination $d r$, that there is a demand for giving a reason for the classified following activity, or to indicate by using the combination $r d$, that there is given a reason why the following demand is made.

\section{RESULTS AND DISCUSSION}

The students' answer is shown in the dialogue in Table 2 (the right column gives a reason for the chosen classification). This dialogue is taken from the fifth lesson. First, it shows that for an external teacher, it was possible to change the general behavior of answering questions of the teacher in quite a short time: it is at this time not the behavior as Sembiring et al. (2008) describes in their chapter "State of the art of Indonesian mathematics education and the need for reform." It shows that the student had been able to compare the two integers. She explained by putting the pawn at the playing field as the first position and then looked at the second position, compared these two positions, and decided that the first position is smaller than the second position. The small transcript shows that the student can practice the metacognitive activity while she works on this exercise. But most of the time, she still needs the demand of the teacher for giving a reason. 
Table 2. The answer of the student

Teacher: Norbeth, how do you solve this exercise [exercise a]

Student:

Teacher: How do you know that the pawn is at minus 3?

Student:

Teacher:

Student:

Teacher:

Student:

Teacher:

Then?

Student: The pawn is at the left of zero. So, we put the sign smaller than [The student wrote smaller than between minus 3 and zero]

Teacher: Why do you have to put the sign "smaller than"?

Student: Because it is on the left.

Teacher: What do you mean by "on the left"?

Student: The pawn is on the left of zero.
P2

The teacher starts with an open question; she offers, e.g., an opportunity to the student for reflection with a reason.

$d r \mathrm{R} 1 \mathrm{a} \quad$ The teacher demands an analysis of the structure of the given term with reason.

rR1a The student gives a reason.

$d r \mathrm{R} 1 \mathrm{a} \quad$ The teacher demands a reason for the answer.

$r \mathrm{R} 1 \mathrm{a}$ The student gives a reason. It is only an encouragement to continue, not a demand for a specific metacognitive activity; therefore, it is not classified.

R6a The student points out the critical aspect.

$d r \mathrm{R} 3 \mathrm{~b} \quad$ The teacher demands a reason for the chosen symbol.

$r \mathrm{R} 3 \mathrm{~b} \quad$ The student gives a reason.

$d \mathrm{M} 2 \quad$ The teacher demands to control the terminology used.

M2 The student improves her terminology.

After that, the students play games with the rules which are given by the game. The result is shown in Figure 5.

\begin{tabular}{|c|c|c|}
\hline $\begin{array}{l}\text { Kombinssi dodu arats } \\
\text { seraken }\end{array}$ & $\begin{array}{l}\text { Powisi } \\
\text { nkkhir }\end{array}$ & $\begin{array}{l}\text { Pennolisan seseral } \\
\text { matematüasa }\end{array}$ \\
\hline$\left(\begin{array}{ll|l}0 & 0\end{array}\right)$ & $(-1)$ & $(0-1)=(-1)$ \\
\hline$((-1)+\infty)$ & 0 & $(-1)+9)=0$ \\
\hline$(0)+4)$ & 4 & $(0+4)=4$ \\
\hline$(4)+(-(-5))$ & $(-1)$ & $\left(u+\left(3 y_{1}\right)\right)</ 4$ \\
\hline$(\mid-1)+(-(2))$ & $(-3)$ & $(-1-1)+(-2)=(-3)$ \\
\hline$((-3)+\infty)$ & 1 & $(-3)+u)=1$ \\
\hline
\end{tabular}

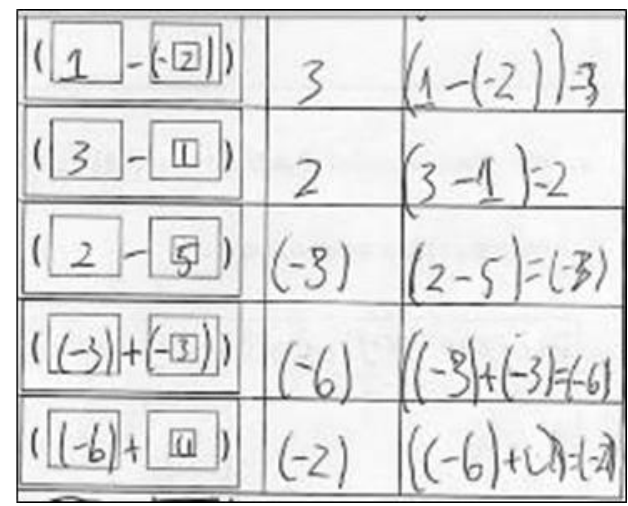

Figure 5. The students' answer

Based on the Figure 5 in line 1, the pawn is at zero position and jumps backward 1 step so that the final position of the pawn is at (-1). Then the students learn how this task corresponds to the notation of a traditional arithmetical problem. Notation is a part of the definition of negative numbers. It is $(0-1)=$ $(-1)$.

The notation in line 2 is a part of the theorem that can be proven based on the axiomatic system given by the game. It is $(-1)+1=0$ or in general it can be written as one theorem $((-a)+a)=0$. The notation in line 3 is a part of one axiom. It is $(0+4)=4$ or in general it can be written as $(0+a)=a$. In lines $4-6$ and $10-11$, the students have been able to determine the addition of integers based on the rule given by the game. In lines $7-9$, the students have been able to determine the subtraction of integer based on the rule given by the game. After about six lessons, the students were given the problem as follows: 
The pawn is at 2. What are the dice for moving direction and the number dice so that the final position of the pawn is at (-1)? The student answer can be seen in the dialogue in Table 3 .

Table 3. The student answers

\begin{tabular}{|c|c|c|c|}
\hline Tiara: & $\begin{array}{l}\text { First, the pawn is at } 2 \text {. The final position of the } \\
\text { pawn is at minus } 1 \text {, so the dice for viewing direction } \\
\text { showed backward, and the number dice showed } 3 \text {. } \\
\text { The notation of a traditional arithmetical problem is } \\
(2-3)=-1 \text {. } \\
\text { Turn your pawn to the right based on your viewing } \\
\text { direction and move } 3 \text { steps backward. Turn your } \\
\text { pawn so that its face is looking at you. The final } \\
\text { position of the pawn is at minus } 1 \\
\text { [The students as a pawn moved when Tiara } \\
\text { explained every step. For example: Turn your pawn } \\
\text { to the right based on your viewing direction. The } \\
\text { students, as pawn, turned to the right, etc.] }\end{array}$ & $r \mathrm{R} 4$ & $\begin{array}{l}\text { The student invents a sequence of } \\
\text { activities; this is regarded as an } \\
\text { indication of a tool needed. As the } \\
\text { explanation is quite elaborated, the } \\
\text { classification } r \text { "with reason" is } \\
\text { added. }\end{array}$ \\
\hline Teacher: & $\begin{array}{l}\text { How about you (Meme) based on Tiara's answer } \\
\text { and the pawn? }\end{array}$ & $d \mathrm{M} 4$ & $\begin{array}{l}\text { The teacher demands control of the } \\
\text { validity of the planned result. }\end{array}$ \\
\hline Meme: & Right & M4 & $\begin{array}{l}\text { The student gives a concise answer } \\
\text { without any reason. }\end{array}$ \\
\hline \multirow[t]{2}{*}{ Teacher: } & $\begin{array}{l}\text { Are there any comments? Please look at the front, } \\
\text { on the blackboard. }\end{array}$ & P2 & $\begin{array}{l}\text { The teacher asks an open question } \\
\text { to encourage metacognitive } \\
\text { activities. }\end{array}$ \\
\hline & How about the traditional arithmetical problem? & $d \mathrm{M} 3$ & $\begin{array}{l}\text { The teacher demands a controlling } \\
\text { of the notation. }\end{array}$ \\
\hline Tika: & Yes, it is right & M3 & \\
\hline Asdo: & In minus 1 , there is no parenthesis. & R1 & $\begin{array}{l}\text { The student controls and corrects } \\
\text { the notation. Therefore, it is not } \\
\text { classified simply by M3. }\end{array}$ \\
\hline
\end{tabular}

The difference between the two dialogs shows the students' progress in the quality of argumentation. The student Tiara solved the difficult question and explained her answer systematically in an elaborated manner. Then the teacher did not ask for a correction of the notation, but first, she asked for comments. As there is no response, she demands more narrowly controlling. In line 5, the student Tika cannot see the wrong notation. In line 6 , the student can see that there is no parenthesis in minus 1 without any further demand from the teacher. It means that the student can reflect the wrong notation inside an algebraic structure. In this example, later in the lesson course, the quality of metacognitive activities has improved: On one hand, Tiara gives an elaborated argumentation, and on the other hand, Meme answers by one word. In the end, Asdo continues controlling with reflection without any further demand from the teacher.

After that, the students were divided into two groups. Every group gets the same exercise. The two students from group A and group B present their answers:

Calculate:

$((-10)+(-12))=$

Give your reason

Two students are discussing (see Table 4), and their answers are presented in Figure 6.

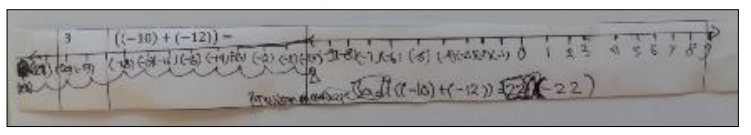

Figure 6. The results of the discussion of two students

Based on students' answers in the worksheet and students' reasoning, it is conjectured that the students can calculate and give a reason in different ways. The progress of students' reasoning in explaining their answers showed that the microworld of the game with precise rules could contribute to 
developing learning to more progressive learning. With a suitable context, the students can construct their understanding of the mathematical ideas which is meaningful for them. The emergence of models supports students' transition from concrete situational problems to more formal mathematics.

Table 4. dialogue between Meme and Asdo

\begin{tabular}{|c|c|c|c|}
\hline Meme: & $\begin{array}{l}\text { First, the pawn is at ..., first, the pawn is at } \\
\text { minus } 10 . \text { Before the pawn ... before the pawn } \\
\text { jumps } 12 \text { steps forward, the pawn has to turn to } \\
\text { the left. The pawn, the pawn jumps } 12 \text { steps } \\
\text { forward. The final position of the pawn is at } \\
\text { minus } 22 \text {. }\end{array}$ & $\begin{array}{l}\mathrm{R} 1 \mathrm{a}, \\
r \mathrm{R} 4\end{array}$ & $\begin{array}{l}\mathrm{S} \text { analysis the structure of the given } \\
\text { expression. Then it translates it into } \\
\text { a movement. This is classified } \\
\text { additionally by } \mathrm{R} 4 \text {, as it is quite } \\
\text { elaborated, it is classified by } r \mathrm{R} 4 \text {. }\end{array}$ \\
\hline \multirow[t]{2}{*}{ Teacher: } & How about you, Asdo? & \multirow[t]{2}{*}{$\mathrm{P} 2$} & \multirow{2}{*}{$\begin{array}{l}\text { T lets it open to the student in which } \\
\text { direction her metacognitive activity } \\
\text { will go (more in the direction of } \\
\text { monitoring or reflection). }\end{array}$} \\
\hline & 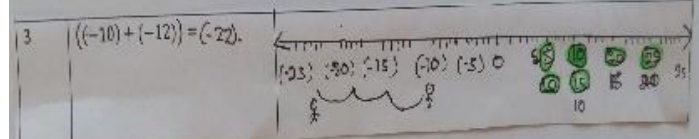 & & \\
\hline Asdo: & $\begin{array}{l}\text { First, the pawn is at minus ten ... minus ten. The } \\
\text { pawn has to turn to the left and jumps } 12 \text { steps } \\
\text { forward. Position, position ... the final position } \\
\text { of the pawn is at } 22 \text {. }\end{array}$ & $\begin{array}{l}\text { R1a, } \\
\text { rR4 }\end{array}$ & $\begin{array}{l}\mathrm{S} \text { analysis the structure of the given } \\
\text { expression. Then it translates it into } \\
\text { a movement. This is classified } \\
\text { additionally by } \mathrm{R} 4 \text {, as it is quite } \\
\text { elaborated, it is classified by } r \mathrm{R} 4 \text {. }\end{array}$ \\
\hline
\end{tabular}

\section{Discussion}

Based on the results that have been described, it can be explained that the game serves as a microworld for understanding the mathematical concepts of whole numbers, their formal descriptions, as well as the formulation of new insights as antecedents of theorems or the defining of new mathematical operations. The game makes fun of the students and trains them to adhere strictly to rules. In such a game, the "meaning" of the figure and its movements is not explicitly defined, but it is a consequence of the complete contract system. It corresponds to the implicit definition of concepts by axiomatic systems. The transition to a contract system (axiomatic system) implies that the experience in the intuitive understood "world" determines how to behave in future situations. Such an approach becomes effective for understanding if only the students repeatedly check the extent to which the new contractual reconstruction relates to their previous intuitive knowledge and the extent to which the formal representation resembles this knowledge.

\section{CONCLUSION}

This design study had been carried out in East-Indonesian Island Sumba, where the mathematical performance of students and their teachers is much below that of the developed parts of Indonesia. However, not only the mathematical competencies are low, more dramatic is the lack of competencies and social traditions to discuss openly in public during lessons: To make a lasting improvement on students' mathematical competencies, the existence of new materials and exercises in lessons alone is not sufficient. Furthermore, the behavior of the learners has to be influenced so that they are being educated to practice metacognitive activities in an elaborated discourse: It was impressive how quickly the students had been acquainted with the demands of the new discussion culture. Educational authorities, who have seen the student's discussions, were quite astonished that there have been no differences between boys and girls, although the Sumbanese society is up to now a very paternalistic one: girls typically do not debate in public against boys. What may be the reasons for this unexpected change? The given microworld offers the possibility of stepwise controllable argumentations. The challenge between controlling and the invention of strategies for actions promotes metacognitive activities. An especially trained teacher can educate even girls at the primary level in argumentations without any fear. The study, therefore, indicates that the cultural differences between societies in developed and developing countries, which are often given as an explanation for the failure of training students in critical thinking, are not a promising explanation. The impressive quick acceptance of the 
approach by the students and their performance in the very unusual format of debating about mathematical ideas raises hope that changes in the quality of teaching are for poorer societies possible without a great economic effort and without first changing their culture.

\section{ACKNOWLEDGMENT}

I am indebted to Elmar Cohors-Fresenborg for his support in designing the teaching sequence and elaborating on the mathematical background.

\section{REFERENCES}

Bofferding, L. (2010). Addition and Subtraction with negatives: Acknowledging the multiple meanings of the minus sign. https://social.education.purdue.edu/bofferding/wpcontent/uploads/2011/08/2010-Bofferding-Addition-and-subtraction.pdf

Brainerd, C. (1979). The origins of the number concept. Praeger.

Cohors-Fresenborg, E. (2013). Das hüpfen auf der zahlenlinie als evidenzbasis für vertragsgemässes rechnen. Beiträge zum Mathematikunterricht 2013, 240-243.

Cohors-Fresenborg, E., \& Kaune, C. (2007). Modeling classroom discussions and categorising discursive and metacognitive activities. In D Pitta-Pantazi \& G Philippou. Proceedings of CERME 5, 1180-1189. University of Cyprus.

Cohors-Fresenborg, E., Kaune, C., \& Zülsdorf-Kersting, M. (2014). Klassifikation von metakognitiven und diskursiven aktivitäten im mathematik- und geschichtsunterricht mit einem gemeinsamen kategoriensystem. Forschungsinstitut für Mathematikdidaktik.

Cohors-Fresenborg, E., \& Nowińska, E. (2021). Pengantar kategorisasi kegiatan metakognitif-diskursif para siswa dan guru dalam pelajaran matematika [Introduction to the categorization of metacognitive-discursive activities of students and teachers in mathematics lessons]. Lembaga Matematika Kognitif - STKIP Weetebula.

Fosnot, C. T., \& Dolk, M. (2001). Young mathematics at work, constructing number sense, addition, and subtraction. Heinemann

Gravemeijer, K., \& Cobb, P. (2006). Design research from a learning perspective. In J. Akker, K. Gravemeijer, S. McKenney, \& N. Nieveen (Eds.), Educational design research (pp. 45-85). Taylor and Francis.

Gray, E., \& Tall, D. (1994). Duality, ambiguity, and flexibility: A "proceptual" view of simple arithmetic. Journal for Research in Mathematics Education, 25(2), 116-140. https://doi.org/10.2307/749505

Muslimin, M., Putri, R. I. I. P., \& Somakim. (2012). Desain pembelajaran pengurangan bilangan bulat melalui permainan tradisional congklak berbasis pendidikan matematika realistik Indonesia di kelas IV sekolah dasar [Learning design on subtraction of integers through the traditional game of congklak based on Indonesian realistic mathematics education in the fourth grade of elementary school]. Jurnal Matematika Kreatif-Inovatif (Kreano), 3(2), 100-112.

https://journal.unnes.ac.id/nju/index.php/kreano/article/view/2642/2710

Musser, G. L., Burger, W. F., \& Peterson, B. E. (2005). Mathematics for elementary teacher: A approach (7th ed.). John Wiley \& Sons.

Nowińska, E. (2015). The benefit of the metaphor "contract" for understanding of concept formation in mathematics. Didactica Mathematicae, 1(36), 58 - 103.

Pintér, K. (2010). Creating game from mathematical problems. Problems, Resources, and Issues in Mathematics Undergraduate Studies, 21(1), 73-90. https://doi.org/10.1080/10511970902889919

Prahmana, R. C. I., Zulkardi, Z., \& Hartono, Y. (2012). Learning multiplication using Indonesian traditional game in third grade. Journal on Mathematics Education, 3(2), 115-132.

https://doi.org/10.22342/jme.3.2.1931.115-132 
Putri, R. I. I. (2011). Implementasi alat peraga operasi bilangan bulat bagi guru sekolah dasar (SD) seKecamatan Ilir Barat I Palembang [Implementation of integer operation teaching aids for elementary school (SD) teachers in Ilir Barat I District, Palembang]. Jurnal Pendidikan Matematika, 5(1), 73-79. https://doi.org/10.22342/jpm.5.1.823

Schneider, W., \& Artelt, C. (2010). Metacognition and mathematics education. ZDM - The International Journal on Mathematics Education, 42(2), 149-161. https://doi.org/10.1007/s11858-010-0240-2

Schwank, I. (1995). The role of microworlds for constructing mathematical concepts. In M. Behara, R. Fritsch, \& R Lintz (Eds.), Symposia Gaussiana, Conference: A mathematics and theoretical physics. Proceedings of the 2nd Gauss Symposium (pp. 101-120). W. de Gruyter.

Schwank, I. (2005). Die schwierigkeit des dazu-denkens. In M. von Aster \& J. -H. Lorenz (Eds.), Rechenstörungen bei kindern - neurowissenschaft, psychologie, pädagogik (pp. 93-133). Vandenhoeck \& Ruprecht.

Schwank, I. (2010). Erlebniswelt zahlen - spielereien mit der rechenwendeltreppe für vorschulkinder. Forschungsinstitut für Mathematikdidaktik.

Schwank, I. (2011). Mathematisches grundverständnis: Denken will erlernt werden. In H. Keller (Ed.), Handbuch der kleinkindforschung: 4 korrigierte, überarbeitete und erweiterte auflage (pp. 11541176). Huber.

Schwank, I., \& Schwank, E. (2015). Development of mathematical concepts during early childhood across cultures. In J. D. Wright (Ed.), The international encyclopedia of the social and behavioral sciences (2nd ed., pp. 772-784). https://doi.org/10.1016/B978-0-08-097086-8.23068-7

Sembiring, R. K., Hadi, S., \& Dolk, M. (2008). Reforming mathematics learning in Indonesia classrooms through RME. ZDM-The International Journal on Mathematics Education, 40(6), 927-939. https://doi.org/10.1007/s11858-008-0125-9

Van de Walle, J. A., Karp, K. S., \& Bay-Williams, J. M. (2008). Elementary and middle school mathematics: Teaching developmentally (8th ed). Pearson.

Veenman, M., Van Hout-Wolters, B., \& Afflerbach, P. (2006). Metacognition and learning: Conceptual and methodological considerations. Metacognition and Learning, 1(1), 3-14. https://doi.org/10.1007/s11409-006-6893-0

Zulkardi, Z. (2002). Developing a learning environment on realistic mathematics education for Indonesian student teachers [Doctoral dissertation, University of Twente]. Sriwijaya University Institutional Repository. http://doc.utwente.nl/58718/1/thesis_Zulkardi.pdf 